\title{
luxRI homologs are universally present in the genus Aeromonas Kamlesh Jangid ${ }^{1,2}$, Richard Kong 3 , Milind S Patole ${ }^{1}$ and Yogesh S Shouche*1
}

\author{
Address: ${ }^{1}$ Molecular Biology Unit, National Centre for Cell Science, University of Pune, Pune- 411007, Maharashtra, India, 2527 Biological \\ Sciences, Department of Microbiology, University of Georgia, Athens, GA-30602, USA and ${ }^{3}$ Department of Biology and Chemistry, Centre for \\ Coastal Pollution and Conservation, City University of Hong Kong, 83 Tat Chee Avenue, Kowloon Tong, Hong Kong Special Administrative \\ Region, China \\ Email: Kamlesh Jangid - jangidk@uga.edu; Richard Kong - bhrkong@cityu.edu.hk; Milind S Patole - patole@nccs.res.in; \\ Yogesh S Shouche* - yogesh@nccs.res.in \\ * Corresponding author
}

Published: 23 October 2007

BMC Microbiology 2007, 7:93 doi:10.1 186/147|-2180-7-93

This article is available from: http://www.biomedcentral.com/I47I-2/80/7/93

(c) 2007 Jangid et al; licensee BioMed Central Ltd.

This is an Open Access article distributed under the terms of the Creative Commons Attribution License (http://creativecommons.org/licenses/by/2.0), which permits unrestricted use, distribution, and reproduction in any medium, provided the original work is properly cited.
Received: 2I March 2007

Accepted: 23 October 2007

\begin{abstract}
Background: Aeromonas spp. have been regarded as "emerging pathogens". Aeromonads possess multifactorial virulence and the production of many of these virulence determinants is associated with high cell density, a phenomenon that might be regulated by quorum sensing. However, only two species of the genus are reported to possess the luxRl quorum sensing gene homologs. The purpose of this study was to investigate if the luxRI homologs are universally present in the Aeromonas strains collected from various culture collections, clinical laboratories and field studies.

Results: Of all the 73 Aeromonas strains used in the study, seventy-one strains elicited acylhomoserine lactone-mediated response in multiple biosensor strains. However, dot blot hybridization revealed that the luxRI homologs are present in all the strains. PCR amplification and sequencing revealed that the luxRI homologs shared a very high percentage sequence similarity. No evidence for lateral gene transfer of the luxRI homologs between aeromonads and other genera was noted.

Conclusion: We propose that the luxRI quorum sensing gene homologs are universally present in the genus Aeromonas independently from their origin. This study is the first genus-wide report of the taxonomic distribution of the luxRI homologs.
\end{abstract}

\section{Background}

The genus Aeromonas is a medically important genus in the family Aeromonadaceae within the $\gamma$-Proteobacteria [1]. Aeromonas species, referred to as "emerging pathogens" [2], are suspected to cause multiple infections in humans $[3,4]$. In addition, they cause diseases in amphibians, reptiles and fish [5]. They are more frequently isolated from samples of medical importance than from environmental sources [6,7]. Their multifactorial virulence determinants include surface associated factors like adhesins, extracellular proteins like siderophores for iron acquisition, and exoenzymes and exotoxins like $\alpha$-haemolysin and serine proteases amongst others. The expression of many of these virulence determinants is associated with high cell densities [8-11] and are therefore putatively under control by quorum sensing.

Quorum sensing is a density-dependent regulation of the gene expression by self-generated signal molecules, such as the acyl-homoserine lactones (AHLs) in gram-negative bacteria. In A. hydrophila, the serine- and metalloprotease activities [12,13], biofilm development [14], and butane- 
diol fermentation [15] are under quorum sensing control. Although, the AHL mediated production of extracellular proteases in A. hydrophila is decreased in the presence of long chain AHLs [12], mutations in its luxRI homologs do not affect its virulence towards gnotobiotically cultured Artemia franciscana [16]. Hence, a decrease in the expression of a virulence factor does not necessarily correlate with decreased virulence. Unfortunately only two species of this genus, A. hydrophila and A. salmonicida, are known to harbour the quorum sensing mechanism as opposed to the majority of Aeromonas spp. with known pathogenic potential [17]. It therefore necessitates investigating the distribution of this mechanism throughout this genus.

Despite the diversity of the phenotypes that are regulated by the quorum sensing network, luxR and luxI constitute evolutionary conserved gene families. luxRI homologs can be identified in most species in which AHL based quorum sensing is known to operate, although some alternative AHL synthases do exist [18]. Species can also possess differing number of luxR and luxI homologs or even a luxR homolog alone [19]. The AHL-mediated gene expression machinery is reportedly conserved within a particular genus and the species within that share very high sequence similarities with each other. In-between various genera within a family, even though there are certain highly conserved regions, the overall levels of sequence similarity are often very low and range between $18-25 \%$ and $28-35 \%$ for LuxR and LuxI homologs, respectively [20].

The environmental distribution of the AHL-mediated gene expression systems amongst bacteria is very poorly understood. Merely $2.2 \%$ (21 bacterial genera) of the total number of bacterial genera listed in the Bergey's Manual of Systematic Bacteriology [21], are known to harbour the AHL producing species, and all of which belong to the $\alpha$-, $\beta$ - and $\gamma$-Proteobacteria only [22]. Unfortunately, at the species level this percentage drops to a fraction of a percent. Although few reports are known about the AHLmediated gene expression by bacterial strains isolated from contact lens wearers [23], marine snow [24], and rumen [25], not many reports are available on the existence of this system across bacterial genera or within a genus. For instance, only two species of the genus Aeromonas are known to harbour the genes for quorum sensing mechanism [17]. The importance of this mechanism demands that the existence and distribution of AHLmediated gene expression systems be studied across bacterial taxa.

With a view that there is a considerable sequence similarity in the AHL-mediated machinery within a genus, it may be possible to PCR amplify the luxRI homologs either individually or together. This hypothesis was tested in the present study using the genus Aeromonas as a model system to investigate if the luxRI quorum sensing gene homologs are universally present in this genus.

\section{Results \\ $A H L$ production by Aeromonas strains}

A total of 71 strains tested positive for AHL production. Of the 73 strains screened, 70 strains elicited AHL-mediated violet pigmentation in the Chromobacterium violaceum CV026 strain within $24 \mathrm{~h}$. Amongst the three remaining strains which tested negative with the CV026 assay, one strain, Aeromonas sp. ATCC $43946^{\mathrm{T}}$ (Hybridization Group, HG-13) elicited $g f p$ expression in E. coli JM109 harboring pJBA89 in $24 \mathrm{~h}$ as observed in CLSM imaging analysis (Fig. 1). Two strains: A. hydrophila ATCC $7966^{\mathrm{T}}$ (HG-1) and A. hydrophila CDC 0434-84 (HG-3) tested negative in all the three bioassays. No variation in the observations was noted when extracted AHLs from culture supernatant were screened similarly. Surprisingly, no inhibition of violet pigmentation in the CV026 reverse assay was noted for the three negative strains.

\section{Molecular detection of the luxRI homologs}

All the seventy-three strains possessed the luxRI homologs as revealed by dot blot hybridization. Interestingly, the three strains that tested negative with the CV026 bioassay showed the presence of luxRI homologs (Fig. 2). Although, the PCR amplification of the complete regulon resulted in no success that of the individual gene fragments (luxR and luxI homologs) was successful. The amplification of the luxR homolog using the gene specific primer pair, QS-722F and QS-1444R produced a reproducible single DNA fragment ( $790 \mathrm{bp}$ ) from seventy strains. The three exceptions were: A. caviae strains RK 217455 and RK 25447, and the recently reported A. molluscorum LMG $22214^{\mathrm{T}}$ [26]. The amplification of the luxI homolog using the degenerate primer pair QS-24F and QS-697R resulted in partial success. PCR amplification with the primer pairs designed specifically for the luxRI homologs from A. culicicola MTCC 3249', AcuRF/AcuRR and AcuIF/AcuIR, resulted in desired size fragment amplification for more strains. All these PCR products were then purified, sequenced and confirmed to be luxRI homologs. We were successful in PCR amplifying the luxR and luxI homologs from 70 and 34 strains, respectively.

\section{luxRI homolog sequence analysis}

The luxR homologs showed a wide range of sequence similarity. The percentage sequence similarity ranged from $79.28-100 \%$ corresponding to $0-161$ nucleotide differences (Additional file 1 available online). Similarly, the inter-species nucleotide substitution rates were spread out $(0.89-20.46 \%)$. While the least values were shared between the type strains of $A$. bestiarum/A. caviae and $A$. bestiarum/A. encheleia, the maximum values were between 

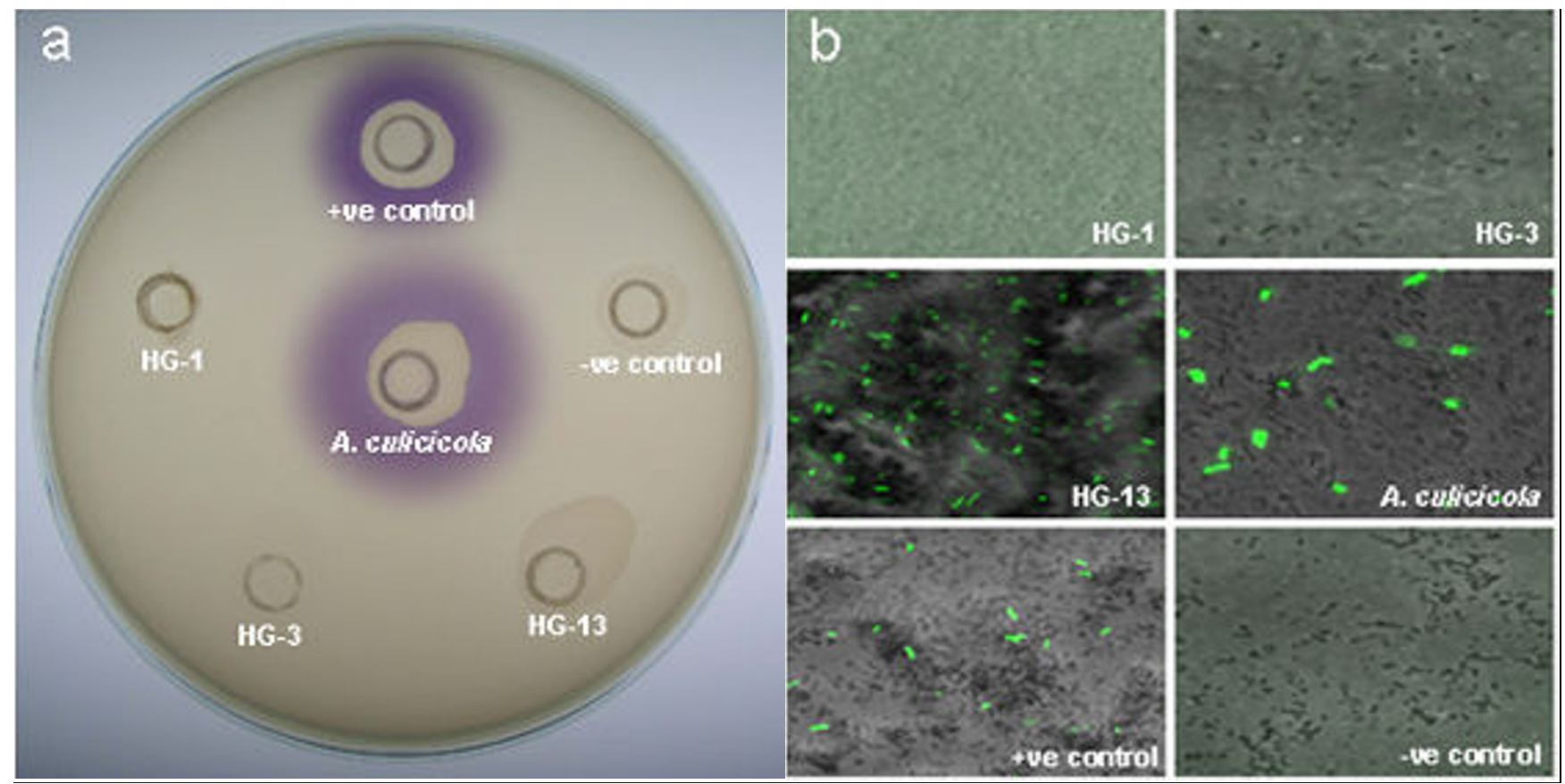

\section{Figure I}

Biosensor based detection of AHL production by Aeromonas strains. a) Chromobacterium violaceum CV026 assay plate with both controls alongwith A. culicicola MTCC 3249' and the three negative strains; and b) CLSM images of gfP expression from E. coli JMI09 harboring PJBA89 in the presence of spent culture supernatants from all the six strains as in a) showing positive result for HG-I3.

A. media (HG-5A)/A. culicicola. Similar nucleotide substitution rates were also observed at the intra-species level (0.26-17.24\%). The luxR homologs varied in size from 777-786 nucleotides. A total of 331 variable positions ( $42.11 \%$ of the sequenced region) of which a very high proportion of parsimoniously informative sites $\left(P_{i}\right)$ was observed $(31.67 \%)$. Indels were noted at specific positions in nine strains (Fig. 3). A. hydrophila ATCC $7966^{\mathrm{T}}$ possessed a single triplet insertion (CAT) at position 402 while deletion of two nucleotide triplets was detected at position 530 of the luxR homologs in six other strains (A. sobria CIP 7433' ; A. culicicola strains MTCC $3249^{\mathrm{T}}$, SH and SLH; A. veronii bv sobria CECT 4246; and A. trota AN-35). The nucleotide positions are as per the luxRI homologs [GenBank:X89469] in A. hydrophila [17].

The luxI homologs showed lower sequence similarity. The percentage sequence similarity ranged from $69.34-100 \%$ (Additional file 2 available online). The luxI homolgs varied in length from 624-639 nucleotides. A total of $237 P_{i}$ sites ( $82 \%$ of the total 289 variable positions) were observed. Similar to the luxR homologs, indels were noted in the luxI homologs from nine strains. However, three of these strains were different than the ones with indels in their luxR homologs. These strains were: A. bestiarum strains LMG 13448 and LMG 13662, and A. veronii bv sobria AE-21. In addition, these indels were detected in the 3 ' termini of the sequenced region with most lying in the primer-binding region (data not shown).

\section{Phylogenetic potential of luxRI homologs}

The genus Aeromonas formed a distinct lineage, well separated from other genera in the class Proteobacteria for which the luxR (Fig. 4) and luxI homologs (data not shown) are known. However, some strains of other genera grouped with different genus, indicating possible events of lateral gene transfer (LGT) between them. Multiple tree topologies obtained using other tree-building algorithms were similar with some minor variations in the branch lengths. The phylogenetic trees were based on the nucleotide sequences rather than the amino-acid sequences due to the loss of information in the latter caused by synonymous substitutions as reported earlier [27]. The luxI homologs, similar to the luxR homologs, possessed the ability to discriminate the genus Aeromonas from the other genera in the proteobacterial class. However, the inability to sequence the luxI homologs from all the strains hampered further analysis for this gene.

\section{Discussion}

The disruption of quorum sensing has been suggested as a new strategy for combating disease spread by pathogenic 


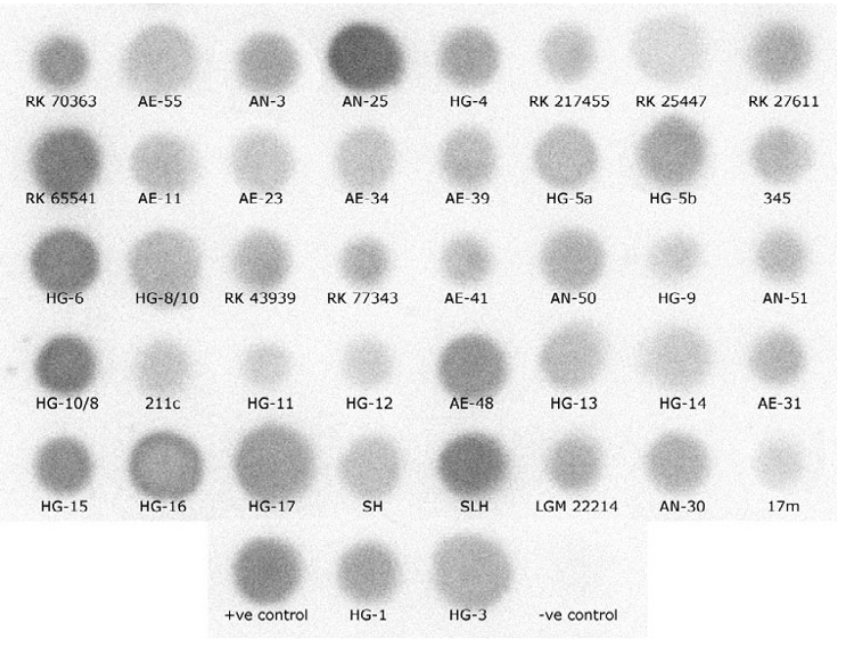

Figure 2

Dot-blot analysis of luxRI gene homologs from

Aeromonas strains. A representative dot-blot showing the presence of luxRI homologs in all the strains that showed no PCR amplification for either luxR or luxl homolog. The negative control (genomic DNA of Selenomonas lipolytica) and positive control (genomic DNA of $A$. culicicola) are also shown.

bacteria. Unfortunately, the scarcity of information on the environmental distribution of this mechanism and the fact that strains of the same species isolated from different ecological niches might possess diverse physiological characteristics, drastically limits the application of this strategy on a genus-wide basis. For instance, species of the genus Aeromonas have been isolated from diverse environments such as the midgut of Culex quinquefasciatus and Aedes aegyptii mosquitoes [28,29], monkey faeces [30], and bivalve molluscs [26], as well as from a variety of foods such as vegetables, raw milk, ice cream, meat and seafood [6,7]. The pathogenic potential of many species of genus Aeromonas indicates the presence of common regulatory machinery amongst strains isolated from different ecological niches. However, only two species of this genus are known to possess the quorum sensing mechanism [17]. In addition, only A. hydrophila has been studied in great detail [12-15]. An understanding of the genus-wide distribution of this mechanism in Aeromonas spp. is the first step towards ascertaining if there are certain common phenotypes under quorum sensing regulation in the genus Aeromonas. This will allow successful implementation of quorum sensing based disease control strategies.

Cell division in the genus Aeromonas may be linked to quorum sensing. Although, there is no experimental evidence, molecular studies in A. hydrophila and A. salmonicida [17] and our analysis of the quorum sensing network in A. culicicola MTCC 3249 (K. Jangid, P. Verma, P. V. Par- ameswaran, M. S. Patole, and Y. S. Shouche, unpublished data) confirmed a gene with close homology to iciA, present downstream of the luxRI homologs. iciA is an E. coli gene encoding a specific inhibitor of chromosomal initiation of replication [31]. The presence of iciA in the genus Aeromonas clearly implicates that cell division may be linked to quorum sensing. The present study on the distribution of the quorum sensing regulatory network in the genus Aeromonas, therefore gains importance.

Earlier studies have reported that some bacterial strains may possess diverse signalling molecules, which cannot be detected by a single biosensor strain [32]. Using multiple biosensor strains would reduce such possibility. Although, possible AHL production from the majority of the strains was detected (Fig. 1), a conclusive evidence of the presence of luxRI homologs was obtained only after dot blot hybridization analysis (Fig. 2). We tested the extracted AHLs to confirm possible inhibition of biosensor strains by some secondary metabolites in the culture supernatant of the three negative strains. In addition, AHLs from upto $100 \mathrm{ml}$ of culture supernatant of these three negative strains were also tested to determine if insufficient AHL quantities yielded the negative results. However, no variation in the results was noted. We hypothesized that regardless of the extent of luxRI homolog sequence similarity shared between Aeromonas strains, the AHLs produced may be diverse and thus not detected by the biosensor strains used. Gene sequencing analyses further validated this hypothesis. The three strains that tested negative in the CV026 bioassay or the reverse assay shared very high luxR homolog sequence similarity ( $94.58 \%$ to $99.36 \%$ ) with the ahyR and asaR sequences [17] (Additional file 1 available online). Moreover, indels were noted in a group of strains at two localized regions in the autoinducer binding domain (amino acid 18-168) of the luxR homologs (Fig. 3). This domain specifically binds to the autoinducer molecules and these indels might therefore be important in autoinducer specificity.

The inability to PCR amplify the complete regulon and the luxI homologs from all strains confirmed previous observations that Aeromonas strains possess greater sequence diversity in luxI as compared to luxR [17]. Preliminary analysis of the percentage sequence similarity and the nucleotide substitution rates for the luxRI homologs support this observation. Our ongoing analysis of the quorum sensing network in A. culicicola MTCC $3249^{\mathrm{T}}$ further supports the hypothesis (Jangid et al., unpublished data). We noted the presence of indels in the binding site of the designed degenerate primers for the luxI homolog from this strain and a $10 \%$ lower sequence similarity value as compared to others [17]. This is contrary to the fact that the luxI homolog sequence similari- 


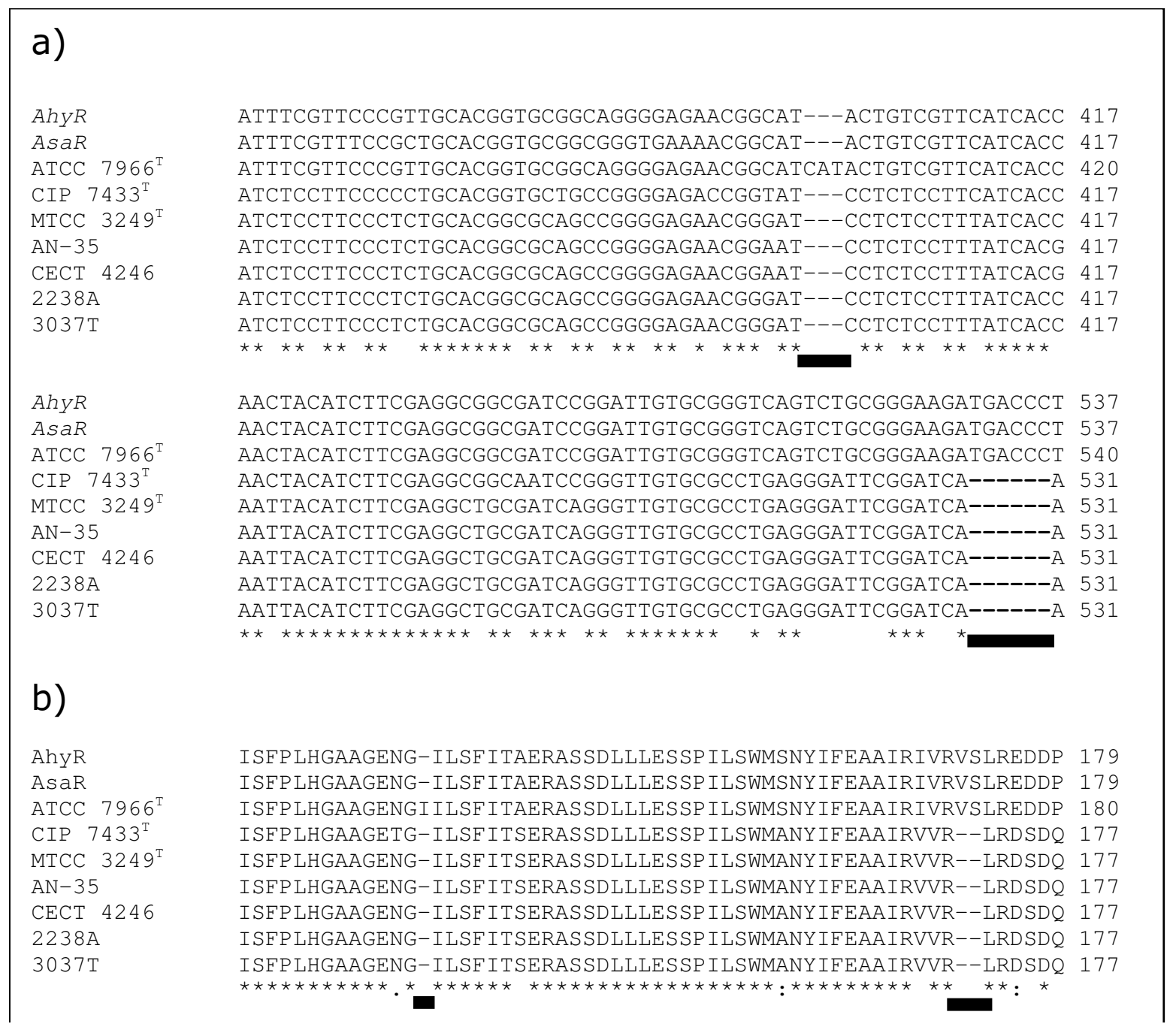

Figure 3

Sequence alignment of the region with indels in the lux $R$ homolog. a) Nucleotide sequence; and b) corresponding amino acid sequence. Sites of insertion/deletion are marked by a solid line.

ties between genera are higher than the corresponding luxR homologs [20].

No evidence of LGT of the luxRI homologs to the genus Aeromonas from another donor was found. All the Aeromonas strains grouped together in a single cluster that was clearly separated from the other members within the Proteobacteria (Fig. 4). However, it is incorrect to conclude that it probably did not occur. It might be possible that if LGT occurred, the donor was probably an organism similar to Aeromonas but not so far included in the analysis. It is even possible that the lineage is currently extinct. From the depth of the branch (Fig. 4), it would seem likely that this organism would moderately be related to Aeromonas but certainly more related than any of the current genera used for the analysis. In case, there was no LGT and if par- alogy occurred, some aeromonads or their ancestors might have had more than one gene for these proteins or that the properties of the proteins might be different for different aeromonads. Both of these scenarios have been discussed in great deal earlier [33]. The same study also reported that the overall congruity between the quorum sensing genes and the rRNA trees is consistent with an ancient origin for the quorum sensing proteins within the Proteobacteria. Our results were however, incongruent with these observations (data not shown). The potential of the luxRI homologs as molecular chronometer and its comparison with the conventional molecular chronometers for the genus Aeromonas has been studied in great detail (K. Jangid, J. M. Gonzalez, W. B. Whitman, G. B. Nair, R. Kong, M. S. Patole, and Y. S. Shouche, unpublished data). 


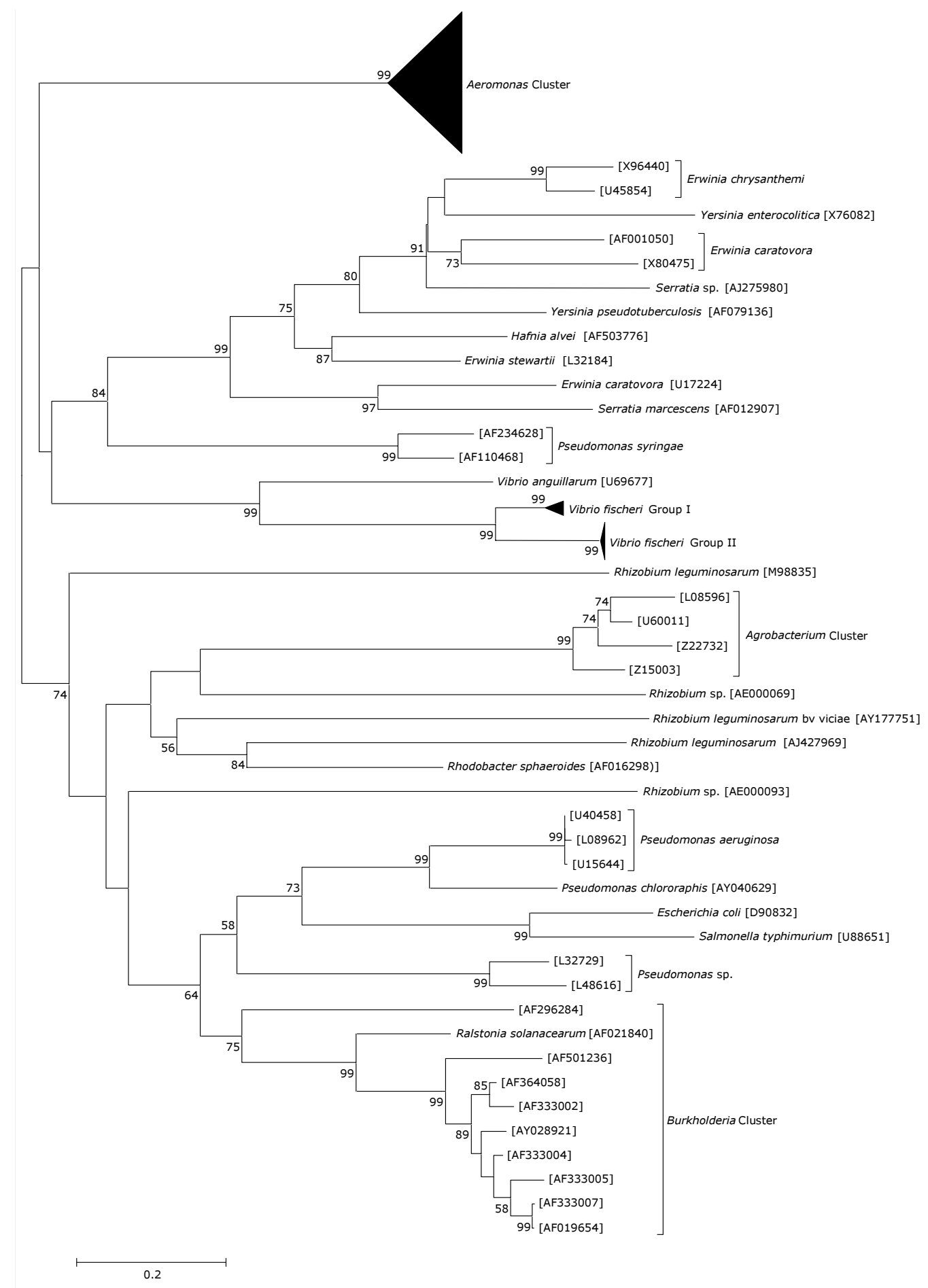

\section{Figure 4}

Proteobacterial luxR homolog based phylogenetic tree. The tree was constructed using the Kimura-2-parameter distances in the neighbor joining method. Values near the nodes represent percentage bootstrap support ( 1000 replicates). Vibrio fischeri Group I [GenBank:M96844, AY292966, AY292967, AY292969, AY292970, AY292979 and AY292980]; and V. fischeri Group II [GenBank:MI9039, M2575I, M25752, Y00509, AFI70104, AY292964, AY292965, AY29297I-AY292978, and AY292982-AY292985]. The GenBank accession numbers of the luxRI homologs from Aeromonas are given in Table I. 


\section{Conclusion}

In conclusion, using both conventional bioassay and molecular approaches, we proved that all the Aeromonas strains used in the study possess the quorum sensing genes irrespective of the nature of the isolates, whether clinical or environmental. The universal presence of the luxRI homologs with high sequence similarity in this genus makes it a potential target for treating Aeromonas borne infections. An understanding of the signaling mechanism in Aeromonas strains from a particular ecological niche would provide a model for bacterial communication among such strains. To our knowledge, this is the first genus-wide study of the taxonomic distribution of luxRI homologs and is the first step in assessing the significance of this mechanism both as a survival strategy and in maintaining ecosystem function.

\section{Methods \\ Bacterial strains, media, and culture conditions}

A total of 73 Aeromonas strains collected from clinical as well as environmental sources and different geographical regions were used in the study (Table 1). Most of the clinical strains were isolated from patients with acute diarrhea over a period of 2 years in Kolkata, India [34]. Eight clinical strains were isolated from stools of diarrhea patients at Queen Mary hospital in Hong Kong, China. The eleven environmental strains were isolated from ovary, salivary gland, or midgut of wild mosquito species collected from across India over a period of 2 years. All these strains were identified based on conventional microbiological and biochemical analysis. In addition, two recently reported A. culicicola strains (2238A and 3037T) from a drinking water supply in Spain were also included [35]. The AHL responsive biosensor strains used were: Chromobacterium violaceum CV026 [36], E. coli JM109 harboring plasmid pSB403 [37] and E. coli JM109 harboring plasmid pJBA89 [38]. These three strains were selected based on earlier reports [36-39] that they could detect a wide range of AHL compounds (Table 2). Although, the plasmid pJBA89 [38] was originally derived from pSB403 [37], the ribosomal binding sites in the former was optimised to detect low concentrations of AHLs and has a $g f p$-fusion which provides low background fluorescence [for details see [38]]. After arrival and/or collection, each bacterial strain was checked for purity on solid medium, and its identity was confirmed by partial sequencing of the $16 \mathrm{~S}$ rRNA gene. All the strains used in the study were maintained on LuriaBertani (LB) medium at $30^{\circ} \mathrm{C}$, except for the A. salmonic$i d a$ strains, which were incubated at $25^{\circ} \mathrm{C}$. Wherever necessary, the medium was supplemented with $50 \mu \mathrm{g}$ of ampicillin $\mathrm{ml}^{-1}, 40 \mu \mathrm{g}$ of kanamycin $\mathrm{ml}^{-1}$ or $20 \mu \mathrm{g}$ of tetracycline $\mathrm{ml}^{-1}$. Cell growth was monitored by measuring the optical density at $600 \mathrm{~nm}$.

\section{Screening for AHL production}

For preliminary screening for AHL production by the Aeromonas strains, $20 \mu \mathrm{l}$ of the culture supernatant from overnight growth was inoculated in wells created onto $\mathrm{LB}$ agar plates seeded with $1 \mathrm{ml}\left(\mathrm{OD}_{600}=1\right)$ of CV026 culture. Visible violet pigmentation was checked after 24-48 $\mathrm{h}$ incubation at $30^{\circ} \mathrm{C}$. The assay with the other two biosensor strains was carried out as described earlier [40]. Bioluminescence was measured after $30 \mathrm{~min}$ incubation. Confocal laser scanning microscope (CLSM) imaging analysis of gfp expression by E. coli JM109 harboring plasmid pJBA89 was done at $10 \times$ using an argon laser at 488 $\mathrm{nm}$ on a Zeiss LSM510 (Jena, Germany). Synthetic AHL standards: BHL (catalogue no. 09945; Fluka), HHL (catalogue no. 09926; Fluka), OHL (catalogue no. 10940; Fluka), DHL (catalogue no. 17248; Fluka) and dDHL (catalogue no. 17247; Fluka) served as controls. Strains, tested negative were processed for AHL extraction from $5 \mathrm{ml}$ culture supernatant using dichloromethane (7: 3::supernatant: dichloromethane). A parallel extraction of the AHLs from A. culicicola MTCC $3249^{\mathrm{T}}$ served as a control. The dried extract was reconstituted in $50 \mu$ l HPLC grade acetonitrile, a $10 \mu \mathrm{l}$ aliquot spot dried onto paper discs (Whatman $3 \mathrm{M}$ ) and processed similarly as above. To detect long-chain AHLs which antagonize activating signals, the three negative strains were also tested using the CV026 reverse assay as described by Swift [39].

\section{Dot blot hybridization, PCR amplification and sequencing} Genomic DNA was prepared by standard phenol/chloroform/isoamyl alcohol extraction [41]. For dot blot hybridization, 1-2 $\mu \mathrm{g}$ of genomic DNA was denatured and spotted ( $2 \mu \mathrm{l}$ aliquots) onto positively charged Nylon membrane (Hybond $\mathrm{N}^{+}$, Amersham Pharmacia Biotech UK Ltd.). Hybridization was performed at $50^{\circ} \mathrm{C}$ for $14 \mathrm{~h}$. Unbound DNA was washed off with $2 \times$ SSC/0.1\% SDS for $20 \mathrm{~min}$ at room temperature followed by a second wash with $0.2 \times \mathrm{SSC} / 0.1 \%$ SDS for $15 \mathrm{~min}$ at $42^{\circ} \mathrm{C}$ for another $20 \mathrm{~min}$. Intensifier screens (Imaging Screen-K, Biorad, USA) were scanned after $30 \mathrm{~min}$ on Molecular Imager FX (Biorad, USA). The A. hydrophila ahyRI fragment [17] was used as the heterologous probe. The probe was random labeled with $\left[\alpha-{ }^{32} \mathrm{P}\right] \mathrm{dATP}$ using the Megaprime DNA labeling system (Amersham Pharmacia Biotech UK Ltd.) as per the manufacturer's instructions. The luxRI homologs were PCR amplified under following conditions: initial denaturation at $95^{\circ} \mathrm{C}$ for $3 \mathrm{~min}, 35$ cycles of denaturation at $95^{\circ} \mathrm{C}$ for $1 \mathrm{~min}$, annealing at $55^{\circ} \mathrm{C}$ for $1 \mathrm{~min}$ and extension at $72^{\circ} \mathrm{C}$ for $1 \mathrm{~min}$ followed by elongation at $72^{\circ} \mathrm{C}$ for $10 \mathrm{~min}$. The details of the primers used are given in Table 3 . The PCR amplified products were purified by $\mathrm{PEG} / \mathrm{NaCl}$ precipitation and sequenced using the PCR primers either on an ABI-310 or ABI-3730 automated DNA analyzer (Applied Biosystems). 
Table I: List of Aeromonas strains used in the study

\begin{tabular}{|c|c|c|c|c|}
\hline \multirow[t]{2}{*}{ Species (Hybridization Group) } & \multirow[t]{2}{*}{ Strain No. } & \multirow[t]{2}{*}{ Isolation site } & \multicolumn{2}{|c|}{ GenBank Accession No. } \\
\hline & & & Luxl & LuxR \\
\hline \multirow[t]{12}{*}{ A. hydrophila (HG-I) } & ATCC $7966^{\top}$ & Tin of milk with fishy odour & AY987564 & AY764300 \\
\hline & ATCC 49140 & Human & AY987586 & AY76435I \\
\hline & RK 217215 & Human faeces & AY987590 & AY764358 \\
\hline & RK 70363 & Human faeces & NS & AY764359 \\
\hline & AE-53 & Patient with acute diarrhea & AY987572 & AY764329 \\
\hline & $\mathrm{AE}-55$ & Patient with acute diarrhea & NS & AY764330 \\
\hline & AE-57 & Patient with acute diarrhea & AY987573 & AY764331 \\
\hline & AN-I & Patient with acute diarrhea & AY987574 & AY764332 \\
\hline & $\mathrm{AN}-2$ & Patient with acute diarrhea & $\overline{\text { AY987575 }}$ & AY764333 \\
\hline & AN-3 & Patient with acute diarrhea & NS & AY764334 \\
\hline & AN-25 & Patient with acute diarrhea & NS & AY764336 \\
\hline & AN-32 & Patient with acute diarrhea & $\underline{\text { AY9 } 987577}$ & AY764338 \\
\hline \multirow{6}{*}{ A. bestiarum (HG-2) } & ATCC $51108^{\top}$ & Infected fish & AY987565 & AY76430I \\
\hline & ATCC I3444 & Ditch water & AY987587 & AY764352 \\
\hline & ATCC 2321I & Water supply & AY987588 & AY764353 \\
\hline & ATCC 23213 & River water & AY987589 & AY764354 \\
\hline & LMG I3448 & Human faeces & $\overline{\text { AY987581 }}$ & AY764346 \\
\hline & LMG 13662 & Faeces & AY987582 & AY764347 \\
\hline \multirow{2}{*}{ A. salmonicida (HG-3) } & CECT $894^{\top}$ & Salmon, Salmo salar & AY987583 & AY764348 \\
\hline & CDC 0434-84 & Freshwater & AY987566 & AY764302 \\
\hline \multirow[t]{9}{*}{ A. caviae (HG-4) } & ATCC $15468^{\top}$ & Epizootic of young guinea pigs & NS & AY764303 \\
\hline & RK 217455 & Human faeces & NS & NS \\
\hline & RK 25447 & Human faeces & NS & NS \\
\hline & RK 276II & Human faeces & NS & AY764355 \\
\hline & RK 6554I & Human faeces & NS & AY987549 \\
\hline & AE-II & Patient with acute diarrhea & NS & AY764321 \\
\hline & $\mathrm{AE}-23$ & Patient with acute diarrhea & NS & $\overline{\text { AY764323 }}$ \\
\hline & $\mathrm{AE}-34$ & Patient with acute diarrhea & NS & AY987548 \\
\hline & $A E-39$ & Patient with acute diarrhea & NS & AY764325 \\
\hline A. media (HG-5A) & CDC 0862-83 & Infected fish & NS & AY764304 \\
\hline \multirow[t]{2}{*}{ A. media (HG-5B) } & ATCC $33907^{\top}$ & Fish farm effluent & NS & AY764305 \\
\hline & 345 & NA & NS & $\overline{\text { AY764344 }}$ \\
\hline A. eucrenophila (HG-6) & ATCC $23309^{\top}$ & Freshwater fish & NS & AY764306 \\
\hline A. sobria (HG-7) & CIP $7433^{\top}$ & Fish & AY987567 & AY764307 \\
\hline \multirow[t]{7}{*}{ A. veronii bv sobria (HG-8/I0) } & CDC 0437-84 & Infected fish & NS & AY764308 \\
\hline & CECT 4246 & Frog red-leg & AY987580 & AY764345 \\
\hline & RK 43939 & Human faeces & NS & AY764356 \\
\hline & RK 77343 & Human faeces & NS & AY764357 \\
\hline & $A E-2 I$ & Patient with acute diarrhea & AY987570 & AY764322 \\
\hline & AE-4I & Patient with acute diarrhea & NS & AY764326 \\
\hline & AN-50 & Patient with acute diarrhea & NS & AY764341 \\
\hline \multirow[t]{2}{*}{ A. jandaei (HG-9) } & ATCC $49568^{\top}$ & Faeces from patient with diarrhea & NS & AY764309 \\
\hline & AN-5I & Patient with acute diarrhea & NS & AY764342 \\
\hline \multirow[t]{2}{*}{ A. veronii bv veronii (HG- I 0/8) } & ATCC $35624^{\top}$ & Sputum of drowning victim & NS & AY764310 \\
\hline & $21 \mathrm{Ic}$ & NA & NS & AY764343 \\
\hline Aeromonas sp. (HG-I I) & ATCC 3594I & Ankle suture & NS & $\overline{\text { AY76431I }}$ \\
\hline \multirow{2}{*}{ A. schubertii (HG-I2) } & ATCC $43700^{\top}$ & Forehead abscess & NS & AY764312 \\
\hline & AE-48 & Patient with acute diarrhea & NS & AY764327 \\
\hline Aeromonas sp. (HG-13) & ATCC 43946 & Human leg wound & NS & $\mathrm{AY764313}$ \\
\hline \multirow[t]{3}{*}{ A. trota (HG-I4) } & ATCC $49657^{\top}$ & Human faeces & NS & AY764314 \\
\hline & AE-3I & Patient with acute diarrhea & NS & AY764324 \\
\hline & AN-35 & Patient with acute diarrhea & AY987578 & AY764339 \\
\hline A. allosaccharophila (HG-15) & СЕCT 4I99' & Diseased elvers & NS & AY764315 \\
\hline A. encheleia (HG-I6) & СЕСТ $4342^{\top}$ & Healthy juvenile freshwater eel & NS & AY764316 \\
\hline A. popoffii (HG-17) & LMG I754I'T & Drinking water production plant & AY987568 & AY764317 \\
\hline \multirow[t]{4}{*}{ A. culicicola } & MTCC $3249^{\top}$ & Mosquito midgut & AY987569 & AY764318 \\
\hline & $\mathrm{SH}$ & Mosquito midgut & NS & AY764319 \\
\hline & SLH & Mosquito midgut & NS & AY764320 \\
\hline & $2238 \mathrm{~A}$ & Domestic water supply & AY987596 & AY987550 \\
\hline
\end{tabular}


Table I: List of Aeromonas strains used in the study (Continued)

\begin{tabular}{|c|c|c|c|c|}
\hline & 3037T & Domestic water supply & AY987597 & AY98755I \\
\hline A. molluscorum & LMG $22214^{\top}$ & Wedge-shells (Donax trunculus) & NS & NS \\
\hline \multirow[t]{12}{*}{ Aeromonas sp. } & AE-5I & Patient with acute diarrhea & AY98757I & AY764328 \\
\hline & AN-24 & Patient with acute diarrhea & AY987576 & AY7643335 \\
\hline & AN-30 & Patient with acute diarrhea & NS & AY764337 \\
\hline & AN-46 & Patient with acute diarrhea & $\underline{\text { AY987579 }}$ & AY764340 \\
\hline & Manipal AI & NA & AY987584 & AY764349 \\
\hline & $A B J$ & Gastric biopsy of gastritis patient & AY987585 & AY764350 \\
\hline & $\mathrm{Im}$ & Mosquito ovary & AY987591 & AY764360 \\
\hline & $12 \mathrm{~m}$ & Mosquito ovary & AY987592 & AY764362 \\
\hline & $13 \mathrm{~m}$ & Mosquito ovary & AY987593 & AY764363 \\
\hline & $15 \mathrm{~m}$ & Mosquito ovary & AY987594 & AY764364 \\
\hline & $17 \mathrm{~m}$ & Mosquito salivary gland & NS & AY764365 \\
\hline & $19 \mathrm{~m}$ & Mosquito ovary & AY987595 & AY764366 \\
\hline
\end{tabular}

NA, Data not available; and NS, not sequenced due to inability to PCR amplify the gene under the conditions used.

Table 2: Range of AHLs detected by the three biosensor strains used in the study

\begin{tabular}{|c|c|c|c|}
\hline acyl-homoserine lactone (AHL) & CV026 & pSB403 & pJBA89 \\
\hline $\begin{array}{l}\text { N-Butanoyl-L-homoserine lacone } \\
\text { (BHL) }\end{array}$ & $\Delta$ & $\circ$ & $\Delta \nabla \Delta$ \\
\hline $\begin{array}{l}\text { N-Butanoyl-L-homocysteine } \\
\text { thiolacone }(\mathrm{BHT})\end{array}$ & $\Delta$ & $\circ$ & $\circ$ \\
\hline $\begin{array}{l}\mathrm{N}-(-3-\mathrm{Oxobutanoyl})-\mathrm{L}-\mathrm{homoserine} \\
\text { lacone }(\mathrm{OBHL})\end{array}$ & $\Delta \nabla \Delta$ & $\circ$ & $\circ$ \\
\hline $\begin{array}{l}\text { N-Benzoylacyl-I-homoserine lactone } \\
\text { (BAHL) }\end{array}$ & $\boldsymbol{\Delta}$ & $\circ$ & $\circ$ \\
\hline $\begin{array}{l}\text { N-Hexanoyl-L-homoserine lacone } \\
(\mathrm{HHL})\end{array}$ & $\boldsymbol{\Delta}$ & $\boldsymbol{\Delta}$ & $\boldsymbol{\Delta}$ \\
\hline $\begin{array}{l}\mathrm{N} \text {-Hexanoyl-L-homocysteine } \\
\text { thiolacone }(\mathrm{HHT})\end{array}$ & $\boldsymbol{\Delta}$ & $\circ$ & $\circ$ \\
\hline $\begin{array}{l}\mathrm{N}-(-3-O x o h e x a n o y l)-L-h o m o s e r i n e \\
\text { lacone }(\mathrm{OHHL})\end{array}$ & $\boldsymbol{\Delta}$ & $\boldsymbol{\Delta}$ & $\boldsymbol{\Delta}$ \\
\hline $\begin{array}{l}\mathrm{N}-(-3-O x o h e x a n o y l)-D-h o m o s e r i n e \\
\text { lacone ((D)OHHL) }\end{array}$ & $\Delta \nabla \Delta$ & $\circ$ & $\circ$ \\
\hline $\begin{array}{l}\mathrm{N}-(-3-O x o h e x a n o y l)-\mathrm{L}- \\
\text { homocysteine thiolacone }(\mathrm{OHHT})\end{array}$ & $\Delta$ & $\circ$ & $\circ$ \\
\hline $\begin{array}{l}\text { N-Octanoyl-L-homoserine lacone } \\
(\mathrm{OHL})\end{array}$ & $\Delta$ & $\boldsymbol{\Delta}$ & $\Delta \nabla \Delta$ \\
\hline $\begin{array}{l}\mathrm{N}-(3-\mathrm{O} x \mathrm{x}-\mathrm{octanoyl})-\mathrm{I} \text {-homoserine } \\
\text { lactone }(\mathrm{OOHL})\end{array}$ & $\Delta$ & $\boldsymbol{\Delta}$ & $\circ$ \\
\hline $\begin{array}{l}\text { N-Decanoyl-I-homoserine lactone } \\
\text { (DHL) }\end{array}$ & $\triangle$ & $\boldsymbol{\Delta}$ & $\circ$ \\
\hline $\begin{array}{l}\mathrm{N} \text {-(3-Oxodecanoyl)-I-homoserine } \\
\text { lactone (ODHL) }\end{array}$ & $\triangle$ & $\boldsymbol{\Delta}$ & $\circ$ \\
\hline $\begin{array}{l}\text { N-Dodecanoyl-I-homoserine lactone } \\
\text { (dDHL) }\end{array}$ & $\triangle$ & $\Delta \nabla \Delta$ & $\circ$ \\
\hline $\begin{array}{l}\mathrm{N}-(3-O x o d o d e c a n o y l)-\text {--homoserine } \\
\text { lactone (OdDHL) }\end{array}$ & $\triangle$ & $\Delta \nabla \Delta$ & $\circ$ \\
\hline $\begin{array}{l}\mathrm{N} \text {-Tetradecanoyl-I-homoserine } \\
\text { lactone (tDHL) }\end{array}$ & $\triangle$ & $\circ$ & $\circ$ \\
\hline $\begin{array}{l}\mathrm{N}-(3-\text {-Oxotetradecanoyl)-I- } \\
\text { homoserine lactone (OtDHL) }\end{array}$ & $\triangle$ & $\circ$ & $\circ$ \\
\hline
\end{tabular}

" $\boldsymbol{\Delta}$ " indicates a suitable biosensor; " $\boldsymbol{\Delta} \boldsymbol{\nabla} \boldsymbol{\Delta}$ " indicates that the sensor will detect the AHLs at high concentration; " $\triangle$ " indicates that the sensor will antagonize AHL-mediated induction; and "o" indicates data not available. The data presented here was previously reported [3639].

\section{Phylogenetic analysis}

Nucleotide and protein sequence analysis was performed with BLAST [42]. The sequences were aligned using the CLUSTALW v1.83 at the European Bioinformatics site [43]. The GenBank accession numbers for the sequences are given in Table 1. In addition, the two previously reported Aeromonas luxRI homolog sequences [GenBank:X89469 and U65741] were also used. The sequence similarity matrix was prepared using the DNAdist program in the PHYLIP package [44] using the Jukes Cantor corrections. The phylogenetic trees were constructed with the neighbor joining method using Kimura-2-parameter distances in MEGA v3.1 [45]. The resulting trees were compared with the parsimony method (100 bootstrap replicates) in the PHYLIP package and with the maximum-likelihood method using the fastDNAml program [46].

\section{Authors' contributions}

$\mathrm{KJ}$ carried out the molecular genetic studies, sequence retrieval and analysis and drafted the manuscript. KJ, RK, MSP and YSS conceived of the study, and participated in its design and coordination. YSS was also involved in the analysis and interpretation of results and drafting the

Table 3: List of primers used in the study

\begin{tabular}{ll}
\hline Primer Name* & \multicolumn{1}{c}{ Primer Sequence (5' to 3') } \\
\hline QSH-24F & TTA TTC TGT GAC CAG TTC GCG CGC \\
QS-24F & TTA YTC KGT GAC CAG TTC SCK SGC \\
QS-697R & GGT CTT GTT TCA TAT GCT AGC CCC C \\
QS-722F & GGG GGC TAG CAT ATG AAA CAA GAC C \\
QS-I444R & TTA TTG CAT CAG CTT GGG GAA GTT G \\
AculF & ATG TTG GTT TTC AAA GGA AAA TTG \\
AculR & TTA TAT CTG GGC CGC TAA CTC ATG GGA \\
AcuRF & ATG AAA CAA GAG CAA CTG TTT GAG TAT \\
AcuRR & CTA TTG CAT CAG TTT AGG GAA GTT GGT
\end{tabular}

'*'- Numbers in the primer name indicate the 3 ' end binding site with respect to A. hydrophila sequence [GenBank:X89469]. 
manuscript. All authors read and approved the final manuscript.

\section{Additional material}

\section{Additional file 1}

Similarity Matrix for the luxR homologs. Percentage sequence similarity (lower left) and number of nucleotide differences (top right).

Click here for file

[http://www.biomedcentral.com/content/supplementary/1471-

2180-7-93-S1.pdf]

\section{Additional file 2}

Similarity Matrix for the luxI homologs. Percentage sequence similarity (lower left) and number of nucleotide differences (top right).

Click here for file

[http://www.biomedcentral.com/content/supplementary/14712180-7-93-S2.pdf]

\section{Acknowledgements}

The authors thank Dr. A. Kaznowski (Department of Microbiology, Poznañ University, Poznan, Poland), Dr. M. J. Figueras (Departament de Ciències Mèdiques Bàsiques, Universitat Rovira i Virgili, Sant Llorenç Spain), Dr. G. Balakrish Nair (International Centre for Diarrhoeal Disease Research, Dhaka, Bangladesh), Prof. P. Williams (Centre for Biomolecular Sciences, University of Nottingham, UK) and Dr. M. Givskov (BioCentrum-DTU, The Technical University of Denmark, Denmark) for providing the strains used in the study. The authors are grateful to Prof. W. B. Whitman (Department of Microbiology, University of Georgia, Georgia) and Dr. J. M. Gonzalez (Departamento de Microbiologia y Biologia Celular, Universidad de La Laguna, Spain) for their critical suggestions to improve the quality of the manuscript.

\section{References}

I. Popoff M: Genus III: Aeromonas Kluvyer and Van Neil 398AL. In Bergey's Manual of Systematic Bacteriology Volume I. Ist edition. Edited by: Krieg NR, Holt JG. Baltimore: Williams \& Wilkins; 1984:545-548.

2. Merino S, Rubires $X$, Knochel $S$, Tomàs JM: Emerging pathogens: Aeromonas spp. Int J Food Microbiol 1995, 28(2): I57-168.

3. Altwegg M, Geiss HK: Aeromonas as a human pathogen. Crit Rev Microbiol 1 989, 16(4):253-286.

4. Janda JM: Recent advances in the study of the taxonomy, pathogenicity, and infectious syndromes associated with the genus Aeromonas. Clin Microbiol Rev 1991, 4:397-4I0.

5. Austin B: Fish pathogenic aeromonads, with emphasis on the ecology of Aeromonas salmonicida. Experientia 1987, 43:358-359.

6. Hänninen ML, Sitonen A: Distribution of Aeromonas phenospecies and genospecies among strains isolated from water, foods or from human clinical samples. Epidemiol Infect 1995, I I 5:39-50.

7. Khardori N, Fainstein V: Aeromonas and Plesiomonas as etiological agents. Annu Rev Microbiol 1988, 42:395-419.

8. Anguita J, Rodriguez-Aparicio LB, Naharro G: Purification, gene cloning, amino acid sequence analysis, and expression of an extracellular lipase from an Aeromonas hydrophila human isolate. Appl Environ Microbiol 1993, 59:24II-24I7.

9. Ljung A, Wretlind B, Molby R: Separation and characterization of enterotoxin and two haemolysins from Aeromonas hydrophila. Acta Pathol Microbiol Scand [B] 198I, 89:387-397.

10. Maclntyre S, Buckley JT: Presence of glycerophospholipid cholesterol acyltransferase and phospholipase in culture supernatants of Aeromonas hydrophila. I Bacteriol 1978, 135:402-407.

II. Whitby PW, Landon M, Coleman G: The cloning and nucleotide sequence of the serine protease gene (aspA) of Aeromonas salmonicida spp. salmonicida. FEMS Microbiol Lett 1992 , 78(I):65-7I.

12. Swift S, Lynch MJ, Fish L, Kirke DF, Tomas JM, Stewart GS, Williams $P$ : Quorum sensing-dependent regulation and blockade of exoprotease production in Aeromonas hydrophila. Infect Immun 1999, 67:5192-5199.

13. Vivas J, Razquin BE, Lopez-Fierro P, Naharro G, Villena A: Correlation between production of acyl homoserine lactones and proteases in an Aeromonas hydrophila aroA live vaccine. Vet Microbiol 2004, 101:167-176.

14. Lynch MJ, Swift S, Kirke DF, Keevil CW, Dodd CE, Williams P: The regulation of biofilm development by quorum sensing in Aeromonas hydrophila. Environ Microbiol 2002, 4:18-28.

15. Van Houdt R, Aertsen A, Michiels CW: Quorum-sensing-dependent switch to butanediol fermentation prevents lethal medium acidification in Aeromonas hydrophila AH-IN. Res Microbiol 2007, I 58:379-385.

16. Defoirdt T, Bossier P, Sorgeloos P, Verstraete W: The impact of mutations in the quorum sensing systems of Aeromonas hydrophila, Vibrio anguillarum and Vibrio harveyi on their virulence towards gnotobiotically cultured Artemia franciscana. Environ Microbiol 2005, 7: 1239-1247.

17. Swift S, Karlyshev AV, Durant EL, Winson MK, Chhabra SR, Williams P, Macintyre S, Stewart GSAB: Quorum sensing in Aeromonas hydrophila and Aeromonas salmonicida: identification of the LuxRI homologues AhyRI and AsaRI and their cognate signal molecules. J Bacteriol I997, I 79:527I-528I.

18. Milton DL, Chalker V], Kirke D, Hardman A, Camara M, Williams P. The LuxM homologue VanM from Vibrio anguillarum directs the synthesis of $\mathbf{N}$-(3-hydroxyhexanoyl) homoserine lactone and N-hexanoylhomoserine lactone. I Bacteriol 200I, 1 83:3537-3547.

19. Sitnikov DM, Schineller JB, Baldwin TO: Control of cell division in Escherichia coli: regulation of transcription of fts $Q A$ involves both rpoS and SdiA-mediated autoinduction. Proc Natl Acad Sci USA 1996, 93:336-341.

20. Fuqua $C$, Winans SC, Greenberg EP: Census and consensus in bacterial ecosystems: the LuxR-Luxl family of quorum-sensing transcriptional regulators. Annu Rev Microbiol 1996, 50:727-75I.

21. Garrity GM, Winters M, Searles DB: Bergey's Manual of systematic Bacteriology 2nd edition. New York: Springer-Verlag; 200I.

22. Manefield M, Turner SL: Quorum sensing in context: out of molecular biology and into microbial ecology. Microbiology 2002, 148:3762-3764.

23. Zhu H, Thuruthyil SJ, Willcox MDP: Production of $\mathbf{N}$-acyl homoserine lactones by gram-negative bacteria isolated from contact lens wearers. Clin Exp Ophthalmol 200 I, 29:150-152.

24. Gram L, Grossart HP, Schlingloff A, Kiørboe T: Possible quorum sensing in marine snow bacteria: production of acylated homoserine lactones by Roseobacter strains isolated from marine snow. Appl Environ Microbiol 2002, 68:4I II-4II6.

25. Mitsumori M, Xu L, Kajikawa H, Kurihara M, Tajima K, Hai J, Takenaka A: Possible quorum sensing in the rumen microbial community: detection of quorum-sensing signal molecules from rumen bacteria. FEMS Microbiol Lett 2003, 219:47-52.

26. Miñana-Galbis D, Farfán M, Carme Fusté M, Lorén JG: Aeromonas molluscorum sp. nov. isolated from bivalve molluscs. Int J Syst Evol Microbiol 2004, 54:2073-2078.

27. Yamamoto S, Harayama S: Phylogenetic analysis of Acinetobacter strains based on the nucleotide sequences of gyrB genes and on the amino acid sequences of their products. Int j Syst Bacteriol 1996, 46:506-5II.

28. Pidiyar VJ, Kaznowski A, Badrinarayan N, Patole MS, Shouche YS: Aeromonas culicicola sp. nov. (MTCC 3249T), from the midgut of Culex quinquifasiatus. Int J Syst Evol Microbiol 2002, 52:1773-I778.

29. Pidiyar VJ, Jangid K, Patole MS, Shouche YS: Studies on cultured and uncultured microbiota of wild Culex quinquefasciatus mosquito midgut based on I6S rRNA gene analysis. Am J Trop Med Hyg 2004, 70:597-603.

30. Harf-Monteil C, Le Flèche A, Riegel P, Prévost G, Bermond D, Grimont PAD, Monteil $\mathrm{H}$ : Aeromonas simiae sp. nov. isolated from monkey faeces. Int J Syst Evol Microbiol 2004, 54:48I-485. 
31. Thony S, Hwang DS, Fradkin L, Kornberg A: iciA, an Escherichia coli gene encoding a specific inhibitor of chromosomal initiation of replication in vitro. Proc Natl Acad Sci USA I991, 88:4066-4070.

32. Winson MK, Camara M, Latifi A, Foglino M, Chhabra SR, Daykin M, Bally M, Chapon V, Salmond GPC, Bycroft BW, Lazdunski A, Stewart GSAB, Williams P: Multiple $\mathbf{N}$-acyl-L-homoserine lactone signal molecules regulate production of virulence determinants and secondary metabolites in Pseudomonas aeruginosa. Proc Natl Acad Sci USA 1995, 92:9427-943I.

33. Gray KM, Garey JR: The evolution of bacterial LuxI and LuxR quorum sensing regulators. Microbiology 200I, I 47:2379-2387.

34. Sinha S, Shimada T, Ramamurthy T, Bhattacharya SK, Yamasaki S, Takeda Y, Nair GB: Prevalence, serotype distribution, antibiotic susceptibility and genetic profiles of mesophilic Aeromonas species isolated from hospitalized diarrhoeal cases in Kolkata, India. J Med Microbiol 2004, 53:527-534.

35. Figueras MJ, Suarez-Franquet A, Chacon MR, Soler L, Navarro M, Alejandre C, Grasa B, Martinez-Murcia AJ, Guarro J: First record of the rare species Aeromonas culicicola from a drinking water supply. Appl Environ Microbiol 2005, 71:538-54I.

36. McClean KH, Winson MK, Fish L, Taylor A, Chhabra SR, Camara M, Daykin M, Lamb JH, Swift S, Bycroft BW, Stewart GSAB, Williams P: Quorum sensing and Chromobacterium violaceum : exploitation of violacein production and inhibition for the detection of $\mathbf{N}$ - acylhomoserine lactones. Microbiology 1997, | 43:3703-37|I.

37. Winson MK, Swift S, Fish L, Throup JP, Jørgensen F, Chhabra SR, Bycroft BW, Williams P, Stewart GSAB: Construction and analysis of luxCDABE-based plasmid sensors for investigating $\mathbf{N}$ acylhomoserine lactone-mediated quorum sensing. FEMS Microbiol Lett 1998, 163:185-192.

38. Andersen JB, Heydorn A, Hentzer M, Eberl L, Geisenberger O, Christensen BB, Molin S, Givskov M: gfp-based $\mathbf{N}$-acylhomoserine-lactone sensor systems for detection of bacterial communication. Appl Environ Microbiol 200I, 67:575-585.

39. Swift S: Quorum sensing: Approaches to identify signals and signalling genes in Gram-negative bacteria. In Prokaryotic genomics: Methods and Tools in Biosciences and Medicine Edited by: Blot M. Switzerland: Birkhauser Verlag Basel; 2003: I I I-I30.

40. Gram L, Christensen AB, Ravn L, Molin S, Givskov M: Production of acylated homoserine lactones by psychrotrophic members of the Enterobacteriaceae isolated from foods. Appl Environ Microbiol 1999, 65:3458-3463.

4I. Sambrook J, Fritsch EF, Maniatis T: Molecular cloning: a laboratory manual 2nd edition. New York: Cold Spring Harbor Laboratory; 1989.

42. BLAST: Basic Local Alignment and Search Tool. [http:// www.ncbi.nlm.nih.gov/blast/].

43. $\mathrm{EBI}$ tools: ClustalW. [http://www.ebi.ac.uk/Tools/clustalw/ index.html].

44. Felsenstein J: PHYLIP- phylogeny inference package v3.2. Cladistics 1989, 5:387-395.

45. Kumar S, Tamura K, Nei M: MEGA3: Integrated software for Molecular Evolutionary Genetics Analysis and sequence alignment. Brief Bioinform 2004, 5(2): I 50- 163.

46. Olsen GJ, Matsuda H, Hagstrom R, Overbeek R: fastDNAml: A tool for construction of phylogenetic trees of DNA sequences using maximum likelihood. Comput Appl Biosci 1994, 10:41-48.
Publish with Bio Med Central and every scientist can read your work free of charge

"BioMed Central will be the most significant development for disseminating the results of biomedical research in our lifetime. "

Sir Paul Nurse, Cancer Research UK

Your research papers will be:

- available free of charge to the entire biomedical community

- peer reviewed and published immediately upon acceptance

- cited in PubMed and archived on PubMed Central

- yours - you keep the copyright

Submit your manuscript here:

http://www.biomedcentral.com/info/publishing_adv.asp
BioMedcentral 